\title{
Nano Titanyum Dioksit Eşliğinde Doğal Organik Maddenin Katalitik Ozonlanması
}

\author{
Alper Alver $^{1 *}$, Emine Baştürk ${ }^{2}$ \\ $1^{*}$ Aksaray Üniversitesi, Teknik Bilimler M.Y.O., Çevre Koruma Teknolojileri Bölümü, Aksaray, Türkiye, (ORCID: 0000-0003-2734-8544), alperalver@gmail.com \\ ${ }^{2}$ Aksaray Üniversitesi, Teknik Bilimler M.Y.O., Çevre Koruma Teknolojileri Bölümü, Aksaray, Türkiye, (ORCID: 0000-0002-1628-5026), \\ eminebasturk@hotmail.com
}

(İlk Geliş Tarihi 24 Mayıs 2021 ve Kabul Tarihi: 15 Ağustos 2021)

(DOI: $10.31590 /$ ejosat.941697)

ATIF/REFERENCE: Alver, A. \& Baştürk, E. (2021). Nano Titanyum Dioksit Eşliğinde Doğal Organik Maddenin Katalitik Ozonlanmas1. European Journal of Science and Technology, (27), 82-88.

\section{$\ddot{O} z$}

Önemli bir bileşeni hümik asitler (HA) olan sulardaki doğal ornaik maddeler (DOM) uğradıkları fiziksel, kimyasal ve biyolojik değişimler sonucunda arıtma tesislerinde çeşitli problemlere sebep olmaktadırlar. Konvansiyonel arıtım prosesleri bu bileşiklerin giderimde yetersiz kaldıkları için ileri arıtım prosesleri ile giderimleri hedeflenmektedir. Son yıllarda en dikkat çekici yöntemlerden biri de katalitik ozonlama prosesleridir. Bu çalışmada $\mathrm{HA}^{\prime}$ nın ozonlama ile oksidasyonunda katalizör olarak nano boyutlu $\mathrm{TiO}_{2}\left(\mathrm{nano} \mathrm{TiO}_{2}\right)$ kullanılmıştır. Katalizörün ozonlama prosesine katkısını belirlemek amacıyla gerçekleştirilen tekil ozonlama, tekil adsorpsiyon ve katalitik ozonlama deneylerinde organik madde konsantrasyonu ve fraksiyonlarındaki değişim çözünmüş organik karbon (ÇOK), UV 254 ve $\mathrm{UV}_{272}$ parametreleri üzerinden takip edilmiştir. UV indekslerinin organik maddenin dezenfeksiyon yan ürünü oluşturma potansiyelinin bir göstergesi olduğu da bilinmektedir. Deneyler sonucunda, organik madde alifatik ve aromatik yapısını bozundurmada katalitik ozonlama prosesinin \%95 üzerinde bir başarım ve \%87 üzerinde ÇOK giderimi sağladığı görülmüştür. Tekil ozonlamanın ve tekil adsorpsiyonun ise HA yapısını bozundurmada kısıtlı kaldığı görülmüştür. Yalancı 1. Derece reaksiyon kinetikleri kıyaslandığında nano- $\mathrm{TiO}_{2} / \mathrm{O}_{3}(0,47801 / \mathrm{dk})$, tekil ozonlamadan $(0,1773 \mathrm{1} / \mathrm{dk})$ neredeyse üç kat, tekil adsorpsiyondan $(0,1047$ 1/dk) neredeyse beş kat daha hızlı gerçekleştiği görülmüştür. Katalitik ozonlama proseslerinin doğal organik madde gideriminde oldukça etkin olduğu ve nano$\mathrm{TiO}_{2}$ katalizörünün serbest radikal oluşturmada başarılı olduğu sonucuna varılmıştır.

Anahtar Kelimeler: Doğal organik madde, Katalitik ozonlanma, Titanyum dioksit, Oksidasyon, Alifatik, Aromatik.

\section{Catalytic Ozonation of Natural Organic Matter via Nano Titanium Dioxide}

\begin{abstract}
Natural organic substances (NOM) in water, an important component of which is humic acids (HA), cause various problems in treatment plants as a result of the physical, chemical and biological changes they undergo. Since conventional treatment processes are insufficient for the removal of these compounds, it is aimed to be removed by advanced treatment processes. One of the most striking methods in recent years is catalytic ozonation processes (cOP). In this study, nano-sized $\mathrm{TiO}_{2}\left(\right.$ nano- $\left.\mathrm{TiO}_{2}\right)$ was used as a catalyst in the oxidation of HA by ozonation. In the single ozonation, single adsorption and catalytic ozonation experiments performed to determine the contribution of the catalyst to the ozonation process, the change in organic matter concentration and fractions was followed by the dissolved organic carbon (DOC), $\mathrm{UV}_{254}$ and $\mathrm{UV}_{272}$ parameters. It is also known that UV indexes are an indicator of the formation potential of disinfection by-product form organic matter. As a result of the experiments, it was observed that the catalytic ozonation process achieved a performance above $95 \%$ and a DOC removal over $87 \%$ in degrading the aliphatic and aromatic structure of organic matter. It has been observed that single ozonation and single adsorption are limited in degrading the HA structure. Comparing pseudofirst order reaction kinetics nano- $\mathrm{TiO}_{2} / \mathrm{O}_{3}(0.4780 \mathrm{l} / \mathrm{min})$ is almost three times faster than single ozonation $(0.1773 \mathrm{l} / \mathrm{min})$ and almost five times faster than single adsorption $(0.1047 \mathrm{l} / \mathrm{min})$ It has been observed to occur. It was concluded that catalytic ozonation processes are highly effective in NOM removal and nano- $\mathrm{TiO}_{2}$ catalyst is successful in generating free radicals.
\end{abstract}

\footnotetext{
*Sorumlu Yazar: alperalver@gmail.com
} 
Keywords: Natural Organic Matter, Catalytic Ozonation, Titanium dioxide, Oxidation, Aliphatic, Aromatic.

\section{Giriş}

Yüzey suları temel içme suyu kaynaklarından biridir ve bu nedenle arıtılmaları tüm dünyada birçok çalışmanın konusu olmuştur. Tüm yüzeysel su kirleticleri içerisinde en çok dikkat organik maddelere verilmektedir (Rucka ve ark., 2019). Doğal organik madde, doğal sulardaki organik karbonun ana kaynaklarından biridir. Doğal sularda bulunan çözünmüş organik madde tipik olarak biojenik, polielektrolitik organik moleküller ve polimerlerden oluşmaktadır (Weber ve ark., 2018). Hümik ve fülvik asitler hem tatlı su hemde deniz ortamlarında bulunan toplam DOM'un yaklaşık \%25-50'sini oluşturuken geriye kalan kısımlar esas olarak proteinler, polisakkaritler, hidrofilik organik asitlerden oluşmaktadır. Hem allokton hemde otokton kaynaklardan türetilen bu organik maddeler çeşitli çevresel ve jeokimyasal dönüşümleri önemli ölçüde etkileyebilmektedir (Waterson Canuel, 2008). DOM'un varlığı, (1) bozunma süreçlerinde ve tanılarında önemli bir rol oynamaktadır, (2) metal kompleksleri oluşturmakta ve bunların doğal sulardaki çözünürlüğünü değiştirmektedir, (3) n-alkanlar, polinükleer aromatik bileşikler ve pestisitler gibi kısmi çözünür elektrolitik olmayan organik çözücüleri bağlamaktadır, (4) yüzey sularındaki fotokimyasal reaskiyonları hassaslaştırmaktadır ve (5) kolloidleri stabilize etmektedir (Grasso ve ark., 1990). Bu nedenle doğal su kaynaklarında DOM'un varlığı su arıtma süreçlerinde geniş kapsamlı sorunlara neden olmaktadır.

DOM hümik ve hümik olmayan maddelere ayrılabilmektedir. Hümik maddeler DOM'un \%90'1 kadar büyük bir bölümünü temsil eder ve dezenfeksiyon yan ürünü (DYÜ) öncüleri olduklarına inanılmaktadır. Hümik maddeler organik maddenin ayrışmaya uğradığı her ortamda bulunmaktadır. Sucul ortamdaki hümik maddelerin iki ana fraksiyonu vardır: doğal sulardan uygun şekilde izole edilen hümik asit (HA) ve fulvik asit. Karmaşık yapılı olarak tanımlanan hümik maddeler, alifatik yan zincirlere sahip aromatik halka yapılarından, özellikle oksijen içeren fonksiyonel gruplardan, oksijen veya nitrojenden oluşan "köprü" birimlerinden ve ilgili karbonhidrat veya peptit fragmanlarından oluşmaktadır (Kulovaara ve ark., 1996). Hümik asidin ortalama moleküler ağırlığı, fulvik asitinkinden daha fazladır (Thurman, 2012). Doğal organik maddenin $U_{2} 24$ ve $U_{2} 272$ dalga boyundaki absorbans değerleri ve absorbans eğimi indeksleri gibi bir dizi UV indeksinin toplam organik halojenler (TOX), trihalometanlar (THM'ler), haloasetik asitler (HAA'lar) ve diğer DYÜ'ler ile iyi korelasyona sahip olduğuna dair birçok literatür çalışması bulunmaktadır (Li ve ark., 2016). Wolska ve ark. (2018) yaptığı çalışmayla benzer olarak, bu çalışmada da UV indeksleri DYÜ'lerin bir göstergesi olarak da kullanılmıştır.

Konvansiyonel arıtma prosesleri organik maddenin yaklaşık \%30'unu giderebilmektedir (Alver, 2019). Bu nedenle verimli bir şekilde DOM giderimi için ileri arıtım yöntemlerine ihtiyaç duyulmaktadır. Sucul ortamdaki organik kirleticilerin parçalanmasında, ileri oksidasyon prosesleri (İOP) başarılı sonuçlarıyla ön plana çıkmaktadır. IOP'lerinden katalitik ozonlama prosesi yaygın olarak kullanılmaktadır.

Ozonlama prosesleri, su ve atık su arıtma alanlarında yüksek oksidasyon ve dezenfeksiyon potansiyeli nedeniyle birçok farklı amaç için yaygın olarak kullanılmaktadır (Zhang ve ark., 2009). Tekil ozonlama proseslerinin, bazı organik bileşiklerle yavaş reaksiyona girmesi, suda nispeten düşük çözünürlükte olması ve doğal organik madde gibi inatçı organik bileşikleri son ürüne kadar okside edememesi gibi dezavantajları vardır (Faria ve ark.,
2009). Bu dezavantajların üstesinden gelmek için, son yıllarda katalitik ozonlama olarak bilinen homojen veya heterojen bir katalizör ile ozonun birlikte kullanıldığı kombinasyonlar araştırılmıştır. Gelecek vaat eden İOP'lerden heterojen katalitik ozonlama, su ve atık su ile ilgili araştırmalarda büyük ilgi görmüştür (Argun ve ark., 2017). Heterojen katalitik ozonlamanın amacı ozonun hidroksil radikallerine dönüşümü yoluyla aromatik fraksiyonu fazla dirençli bileşiklerin oksidasyonunu sağlamaktır. Ayrıca heterojen katalitik ozonlamada kullanılan katalizörün reaksiyon ortamından katalitik geri kazanım kolaylığıda mevcuttur. Literatürde sulardan dirençli organik maddeleri gidermek için ozonlama ile birlikte kullanılmak üzere birçok metal oksit türevi katalizör test edilmiştir.

Son otuz yılda titanyum dioksit $\left(\mathrm{TiO}_{2}\right)$ çevresel arıtma uygulamalarında gelecek vaat eden bir katalizör olarak ortaya çıkmıştır. $\mathrm{TiO}_{2}$ bazlı fotokatalizörlerin 1şık etkinliği ile aktif oksijen üreten oksidasyon reaksiyonları vasitasıyla (örn., $\mathrm{OH}$ radikalleri, hidrojen peroksit, süper oksit anyonları) mikro ve makro ölçekli birçok kirleticiyi verimli bi şekilde bozundurduğu görülmüştür. $\mathrm{TiO}_{2}$ 'nin bu doğal özelliğinden yararlanılarak kendi kendini temizleyen malzemeler, antibakteriyel ve antifungal malzemeler, hava ve su arıtma sistemleri vb. geliştirilmiştir (Alver Basturk, 2019). Hem ticari (anataz, rutil, P25) ölçekli hemde laboratuvar ölçekli sentezlenen $\mathrm{TiO}_{2}$ malzemeleri kirletici içeren sucul çözeltiler içerisine süspanse edilen toz formunda kullanılmaktadır. $\mathrm{Bu}$ uygulama genellikle $\mathrm{TiO}_{2}$ fotokatalistinin sucul ortamdan zahmetli bir şekilde geri kazanılmasına ve geri dönüştürülmesine yol açmaktadır. $\mathrm{Bu}$ nedenle $\mathrm{TiO}_{2}$ için seramik, cam veya fiber gibi katı destek malzemelerinin kullanılması umut verici bir çözümdür (Alver Basturk, 2019).

Bu nedenlerle bu çalışmada nano ölçekli $\mathrm{TiO}_{2}$, sucul ortamdan DOM'ları gidermek için ozonlama işlemlerinde bir katalizör olarak kullanılmıştır. Bu çalışmanın temel amacı, katalitik ozonlamada nano- $\mathrm{TiO}_{2}$ kullanılarak sucul ortamlarda İOP tabanlı bir DOM giderim prosesi geliştirmek ve araştırmaktır. Katalitik ozonlama işleminde nano- $\mathrm{TiO}_{2}$ 'nin katalitik etkisi katalitik ozonlama prosesinin HA giderimindeki etkinliği tekil ozonlama ve tekil nano- $\mathrm{TiO}_{2}$ adsorpsiyon prosesleri ile kıyaslanarak incelenmiştir. Ayrıca nano- $\mathrm{TiO}_{2}$ 'nin DOM bozunması üzerine etkilerini belirlemek için bozunma kinetikleri de araştırılmıştır.

\section{Materyal ve Metot}

\subsection{Hümik Asit Çözeltilerinin Hazırlanması ve Karakterizasyonu}

Çalışmalarda yüzey su kaynaklarında bulunan doğal organik maddeleri temsil etmesi amaciyla hümik asit çözeltileri kullanılmıştır. Ticari hümik asit (H16752) Sigma-Aldrich firmasından satin alınmıştır. Stok çözeltiler, ultrasaf suya belirli miktarlarda Aldrich hümik asiti ilave edilerek ve çözünmeyi kolaylaştırmak için $1.0 \mathrm{~N} \mathrm{NaOH}$ ile $\mathrm{pH} 11$ 'e yükseltilerek hazırlanmıştır. Bir saatlik karıştırma işleminden sonra, $1.0 \mathrm{~N} \mathrm{HCl}$ ile pH yeniden 7'ye ayarlanmış ve çözünmemiş süspanse halde kalan fraksiyonları uzaklaştırmak için çözelti önceden yıkanmış $0,45 \mu \mathrm{m}$ cam elyaf filtreden (Millipore) geçirilmiştir. Stok çözelti konsantrasyonları, çözünmüş organik karbon analizi yapılarak belirlenmiştir. Arıtım çalışmaları yüzey sularını temsil eden 5 $\mathrm{mg} / \mathrm{L}$ konsantrasyonundaki hümik asit çözeltileri ile gerçekleştirilmiştir. HA stok çözeltileri, karanlık ortamda $4{ }^{\circ} \mathrm{C}$ ayarlanmış bir buzdolabında saklanılmıştır. Model çözelti olarak kullanılan Sigma Aldrich hümik asitinin karakterizasyonu Tablo 1 'de verilmiştir. 
Tablo 1. Humik asit çözeltilerinin karakterizasyonu

\begin{tabular}{lccc}
\hline Parametre & Denklem (n=4) & $\mathbf{R}^{\mathbf{2}}$ & $\begin{array}{c}\text { Tespit } \\
\text { Limiti }\end{array}$ \\
\hline $\mathrm{UV}_{254}$, Abs. & $0,0235 \times \mathrm{HA}+0,0209$ & 0,9995 & 0,0015 \\
$\mathrm{UV}_{272}$, Abs. & $0,0211 \times$ HA + 0,0191 & 0,9994 & 0,0018 \\
ÇOK, mg/L & $0,2089 \times$ XA - 0,0608 & 0,9984 & 0,0048 \\
\hline
\end{tabular}

\subsection{Nano Titanyum Dioksit Katalizörü}

Nano ölçekli titanyum dioksit tozu (Ege Nanotek Kimya San.) \%99 saflıkta katalizör süspansiyonlarını hazırlamak için kullanılmıştır. nano- $\mathrm{TiO}_{2}$ 'nin üreticiye göre özgül yüzey alanı 200 $\mathrm{m}^{2} / \mathrm{g}$, gerçek yoğunluğu $4,23 \mathrm{~g} / \mathrm{cm}^{3}$ ve ortalama partikül boyutu 10 nm'dir. nano- $\mathrm{TiO}_{2}$ tozu, analitik hassas terazi kullanılarak tartılmış ve istenilen nano- $\mathrm{TiO}_{2}$ konsantrasyonunu elde etmek için çözeltide süspanse edilmiştir. nano- $\mathrm{TiO}_{2}$ parçacıklarını çözeltide dağıtmak ve homojen bir süspansiyon elde etmek için deneylerde mekanik karıştırma işlemi uygulanılmıştır.

\subsection{Deneysel Prosedür}

Deneysel çalışmaların tamamı oda sıcaklığında gerçekleştirilmiştir. nano- $\mathrm{TiO}_{2}$ 'de $\mathrm{NOM}$ adsorpsiyonu deneyleri katalitik ozonlama deneylerinde kullanılan 1 L çözelti hacimli UV korumalı cam reaktör içerisinde 120 devirde çalıştırılan mekanik karıştırıcı ile gerçekleştirilmiştir. Adsorpsiyon deneyleri nötral pH aralığında $5 \mathrm{mg} / \mathrm{L}$ HA ve $50 \mathrm{mg} / \mathrm{L}$ nano- $\mathrm{TiO}_{2}$ kullanılarak kesikli olarak yürütülmüştür. Deneyler sırasında reaktörden alınan toplam örnek hacminin reaktör hacminin $\% 5$ 'inden fazla olmamasına özen gösterilmiştir. Alınan örnekler, adsorbentin çözeltiden ayrılması için $0,45 \mu \mathrm{m}$ cam elyaf filtreden geçirilmiş ve ÇOK, $\mathrm{UV}_{254}$ ile $\mathrm{UV}_{272}$ analizleri gerçekleştirilmiştir. Adsorpsiyon miktarı (q) ve adsorpsiyon verimliliği sırasıyla Denklem 1 ve Denklem 2'ye göre hesaplanmıştır.

$$
\begin{array}{ll}
\mathrm{q}(\mathrm{mg} / \mathrm{g})=\frac{\left(\mathrm{C}_{\text {giris }}-\mathrm{C}_{\text {denge }}\right) \times V}{M} & \text { Denklem 1 } \\
\text { Ads. }(\%)=\frac{\left(\mathrm{C}_{\text {giris }}-\mathrm{C}_{\text {denge }}\right)}{\mathrm{C}_{\text {giris }}} \times 100 & \text { Denklem 2 }
\end{array}
$$

$\mathrm{C}_{\text {giriş }}$ HA'nın başlangıç konsantrasyonu ve $\mathrm{C}_{\text {denge }}$ HA'nın incelenen süredeki kalan konsantrasyonu, $V$ çözeltinin hacmi ve $M$ ise adsorbanın kütlesini göstermektedir.

Ozonlama deneyleri 1 L çözelti hacimli silindirik UV korumalı cam reaktörde gerçekleştirilmiştir. Oksijen konsantratörü donanımlı ve $0.333 \mathrm{~g} / \mathrm{dk}$ ozon üretim kapasitesine sahip PRO DO 20 ozon jeneratörü (PRODA Group, Türkiye), teflon borular ile cam reaktöre bağlanmıştır. Ayrıca, tüm deney düzeneği bağlantıları ozonla reaksiyona girmeyen malzemelerden seçilmiştir. Kesikli olarak işletilen reaktörün tam karışımı 120 rpm'de dönen mekanik bir karıştırıcı ile sağlanmıştır. Ozonun sudaki çözünürlüğünü artırmak ve istenilen konsantrasyonlarda çözünmüş ozon elde etmek için ozon beslemesi reaktörün alt kısmından ve politetrafloroetilen (PTFE) malzemeden üretilmiş difüzör vasıtası ile gerçekleştirilmiştir. Reaktörden çözünmeden çıkan gaz fazındaki ozonun tutulması için reaktörü takip eden ve içinde \%2'lik KI çözeltisi bulunan 2 adet gaz yıkama şişesi kullanılmıştır. Reaktöre istenilen konsantrasyonlarda hümik çözeltisi ilave edildikten sonra belirli zaman aralıklarında örnekler alınmış ve analizleri yapılmıştır. Analizlerden önce ozon reaksiyonlarını durdurmak amacıyla, alınan örneklere $0.025 \mathrm{M}$ $\mathrm{Na}_{2} \mathrm{SO}_{3}$ ilave edilmiş ve $0.45 \mu$ m'lik cam elyaf filtreden süzülmüştür. Elde edilen filtratta çözünmüş ozon, ÇOK, $\mathrm{UV}_{254}$, $\mathrm{UV}_{272}$ ve SEM/EDS analizleri yapılmıştır.

\subsection{Analiz Yöntemleri}

Spektroskopik ölçümler, Shimadzu UV-1280 marka UV-VIS spektrofotometre ile SM 5910 B (Alver ve ark., 2021) metoduna uygun olarak gerçekleştirilmiştir. HA'nın kimyasal yapısının incelenmesi için takip edilen spesifik karbon bazlı UV-VIS parametreleri $\mathrm{UV}_{254}$ ve $\mathrm{UV}_{272}$ 'dir. Doğal organik maddeler genel olarak hidrofobik özelliktedir. Doğal organik maddelerin oksidantlarla reaksiyonları sonucunda hidrofilik fraksiyonların da artış olmaktadır. $U_{254}$ değerinin hümik maddeler gibi yüksek moleküler ağırlığına sahip organik maddelerin hidrofobikliğinin ve alifatik içeriğinin tespitinde kullanılan önemli bir temsil edici parametre olduğu ortaya konulmuştur (Alver Kılıç, 2021). Bunun yanında $\mathrm{UV}_{272}$ değeri, DOM molekülü ile klor arasındaki reaksiyonlar sırasında fenolik ve hidroksil gibi fonksiyonel gruplar içeren aromatik yapıların bozulmasına karşılık DOM'un UV absorbansında meydana gelen kayıpları göstermektedir (Alver Kılıç, 2021).

Çözünmüş organik karbon analizleri Shimadzu TOCVCPN/TNM-1 cihazı kullanılarak Standart Metotlar 3510 B'de tanımlanan yüksek sicaklıkta yakma metoduna göre gerçekleştirilmiştir (Alver Kılıç, 2018). ÇOK analizleri numuneler $0,45 \mu$ m'lik filtreden süzüldükten sonra gerçekleştirilmiştir.

Çözünmüş ozon analizleri JUMO AQUIS 500 AS ozon analizörü (JUMO Corp. Group, Almanya) ile ASTM D7677 metoduna (International, 2004) uygun olarak sürekli izleme yöntemiyle gerçekleştirilmiştir. $\mathrm{Bu}$ yöntemle yapılan ozon analizleri reaktörden eş zamanlı alınan örneklerde SM 4500-O 3 B İndigo metoduna göre ozon analizleri yapılarak doğrulanmıştır. Sucul ortamda çözünmüş ozon ölçümlerinde kullanılan potasyum indigo trisülfonat Sigma-Aldrich firmasından temin edilmiştir.

Katalizörün karakterizasyonu için SEM ve EDS analizleri, numunelerde altın kaplama işlemi yapılarak FEI marka Quanta FEG 250 model cihaz ile gerçekleştirilmiştir. Farklı büyütme oranlarda en net görüntü elde edilene kadar taramalar devam ettirilmiştir.

Deneysel çalışmaların tüm aşamalarında ACS saflıkta kimyasallar kullanılmıştır. İletkenlik değeri 18,2 M $\Omega$-cm civarı olan ve ÇOK konsantrasyonu $0,02 \mathrm{mg} / \mathrm{L}$ 'den küçük olan ultra safsu, tüm solüsyonların ve partikül süspansiyonlarının hazırlanmasında kullanılmıştır.

\subsection{Kinetik Çalışma}

Bu çalışmada DOM giderimi için temas süresini, optimum q miktarını ve giderim mekanizmasını araştırmak için çeşitli kinetik modeller (yalanc1 1. ve yalancı 2. derece) uygulanmıştır. Yalancı birinci derece kinetik denklemi ilk olarak Lagergren (1898) tarafından tanıtılmıştır ve literatürde, yalancı birinci ve ikinci derece kinetiklerin formülleri genellikle Ho ve McKay tarafindan önerilen lineer formunda kullanılmaktadır (Simonin, 2016) (Tablo 2). 
Tablo 2. Kinetik modeller

\begin{tabular}{lllll}
\hline Kinetik model & Lineer olmayan formu & Lineer formu & Grafik & Eğim ve kesim \\
\hline Yalanc1 1 & $\mathrm{q}_{\mathrm{t}}=\mathrm{q}_{\mathrm{e}}\left(1-\mathrm{e}^{-\mathrm{k}_{1} \mathrm{t}}\right)$ & $\ln \left(\mathrm{q}_{\mathrm{e}}-\mathrm{q}_{\mathrm{t}}\right)=\ln \left(\mathrm{q}_{\mathrm{e}}\right)-\mathrm{k}_{1} \mathrm{t}$ & $\ln \left(\mathrm{q}_{\mathrm{e}}-\mathrm{q}_{\mathrm{t}}\right)$ vs.t & Eğim: $-\mathrm{k}_{1}$, Kesim: $\ln \mathrm{q}_{\mathrm{e}}$ \\
Yalanc1 2 & $\mathrm{q}_{\mathrm{t}}=\frac{\mathrm{q}_{\mathrm{e}}^{2} \mathrm{k}_{2} \mathrm{t}}{1+\mathrm{q}_{\mathrm{e}} \mathrm{k}_{2} \mathrm{t}}$ & $\frac{\mathrm{t}}{\mathrm{q}_{\mathrm{t}}}=\frac{1}{\mathrm{k}_{2} \mathrm{q}_{\mathrm{e}}^{2}}+\frac{\mathrm{t}}{\mathrm{q}_{\mathrm{e}}}$ & $\frac{\mathrm{t}}{\mathrm{q}_{\mathrm{t}}}$ vs.t & Eğim: $\frac{1}{\mathrm{q}_{\mathrm{e}}}$, Kesim: $\frac{1}{\mathrm{k}_{2} \mathrm{q}_{\mathrm{e}}^{2}}$ \\
\hline
\end{tabular}

\section{Araştırma Sonuçları ve Tartışma}

Bu bölümde, doğal organik maddenin tekil ozonlaması, tekil adsorpsiyonu ve katalitik ozonlanması sonrasında sucul ortamdan giderim oranları ve yapısal değişiminin belirlenmesi için laboratuvar ölçekli çalışma gerçekleştirilmiştir. İleri arıtım yöntemlerinin doğal organik maddenin alifatik ve aromatik yapısında oluşturduğu değişimi anlamak için model çözeltilerle çalışmalar yapılmıştır. Ayrıca katalitik ozonlamada katalizör olarak kullanılan nano- $\mathrm{TiO}_{2}$ 'nin katalitik etkisi tekil ozonlama, tekil adsorpsiyon ve katalitik ozonlamadaki DOM giderim hızları kıyaslanarak ortaya konulmaya çalışılmıştır.

\subsection{Tekil Ozonlama ile DOM Giderimi}

Katalitik ozonlama proseslerinde ozonun kirletici ile reaksiyonları 2 yolla gerçeleşmektedir; doğrudan ve dolaylı serbest radikal reaksiyonları (Mathon ve ark., 2021). Ozonun doğrudan kirletici ile reaksiyonua girmesi sucul ortamda hizla tükenmesine ve dolaylı yollarla yani radikallere dönüştükten sonra kirletici ile reaksiyona girmesine göre daha az verimli olmaktadır. $\mathrm{Bu}$ sebeple katalitik ozonlamanın etkinliğinin belirlenebilmesi için tekil ozonlama deneyleri önem arz etmektedir. DOM'un bozunma verimini etkileyen önemli faktörlerden biri de ozonlama proseslerinde uygulanan ozon dozudur. Bu başlık altında $10 \mathrm{mg} / \mathrm{L}$ başlangıç ozon dozunun 5 $\mathrm{mg} / \mathrm{L}$ HA'nın bozunma sürecine etkisi nötr $\mathrm{pH}$ 'ta incelenmiş ve Şekil 1'de gösterilmiştir.

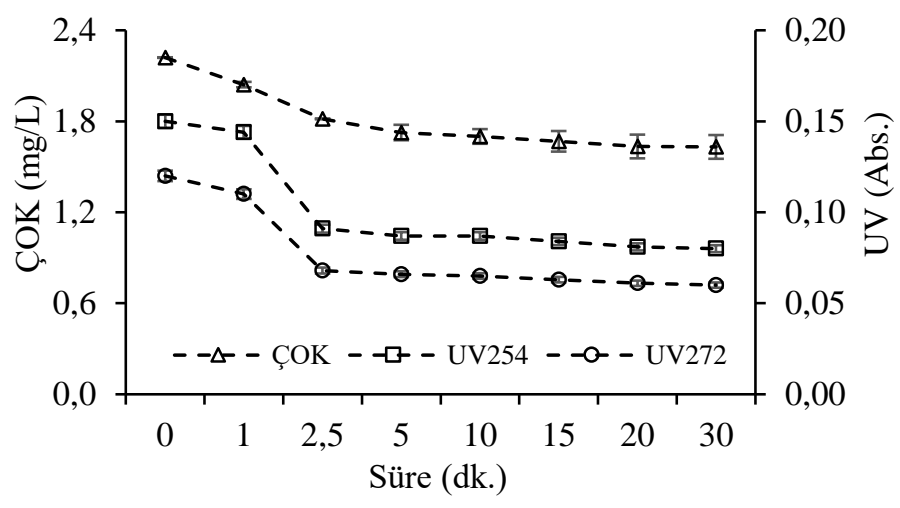

Şekil 1. Tekil ozonlama ile DOM giderimi $\left(\left[\mathrm{O}_{3}\right]=10 \mathrm{mg} / \mathrm{L}\right.$, $[H A]=5 \mathrm{mg} / \mathrm{L}, \mathrm{pH}=7,1 \pm 0,2)$

Ozonun sucul ortamda bozunmaya başlama süreciyle birlikte HA ile reaksiyonları başlamıştır. $10 \mathrm{mg} / \mathrm{L}$ başlangıç ozon dozunun $30 \mathrm{dk}$ süre sonrasında HA'nın bozunmasına ÇOK parametresine göre \%24,86'lık etkisi olmuştur. Literatürde HA'nın ozon uygulanarak bozundurulması, Tablo 3 'te görülebileceği gibi, Yalanc1 1. Derece kinetik modelle tanımlanmaktadır ve reaksiyon hızı Miao ve Tao (2008)'nın çalışmasına benzer olarak 0,1773 $1 / \mathrm{dk}$ hesaplanmıştır. Deneysel şartlar içerisinde tekil ozonlamanın
HA'nın alifatik ve aromatik yapısında ortalama \%45 oranında değişikliğe sebep olduğu tespit edilmiştir. $\mathrm{Bu}$ sonuç hem ozonlamanın kromoforların bölünmesine yol açtığını hem de ozonlama işleminin HA'nın moleküler yapılarını parçalayabileceğini veya yeniden düzenleyebileceğini ve biyolojik olarak parçalanamayan organikleri biyolojik olarak parçalanabilir formlara dönüştürebileceğini göstermektedir. Alifatik ve aromatik yapısal değişiminin ÇOK değişimi ile benzer eğilim gösterdiği görülmektedir. Čehovin ve ark. (2017) yaptıkları çalışmada, $0,3-1,8 \mathrm{~J} / \mathrm{cm}^{2} \mathrm{UV}$ 1şını ve $4-12 \mathrm{mg} / \mathrm{L} \mathrm{H}_{2} \mathrm{O}_{2}$ kullanmışlar ve \%5-15 ÇOK giderimi elde etmişler. Ayrıca daha yüksek ÇOK giderimi için çok yüksek $\mathrm{H}_{2} \mathrm{O}_{2}$ dozlarının kullanılması gerektiği fakat bununda THMOP arttırdığı sonucuna varmışlardır. Bir başka çalışmada ise bromür içeren sularda DOM giderimi için $\mathrm{O}_{3}$ ile birlikte $\mathrm{H}_{2} \mathrm{O}_{2}$ kullanımının THMOP ve HAAOP arttırıdığı raporlanmıştır (Wang ve ark., 2013).

\subsection{Tekil Adsorpsiyon ile DOM Giderimi}

Tekil adsorpsiyon deneyleri, UV korumalı cam reaktör içerisinde $50 \mathrm{mg} / \mathrm{L}$ nano- $\mathrm{TiO}_{2}$ sorbent dozunda, $5 \mathrm{mg} / \mathrm{L}$ 'lik HA konsantrasyonu ve çözelti pH'1 7,2'de sabit tutularak $60 \mathrm{dk}$ boyunca gerçekleştirilmiştir. Temas süresi artışına bağlı olarak organik maddenin ÇOK konsantrasyonundaki ve aromatik ve alifatik fraksiyonlarındaki değişimi Şekil 2'de gösterilmiştir.

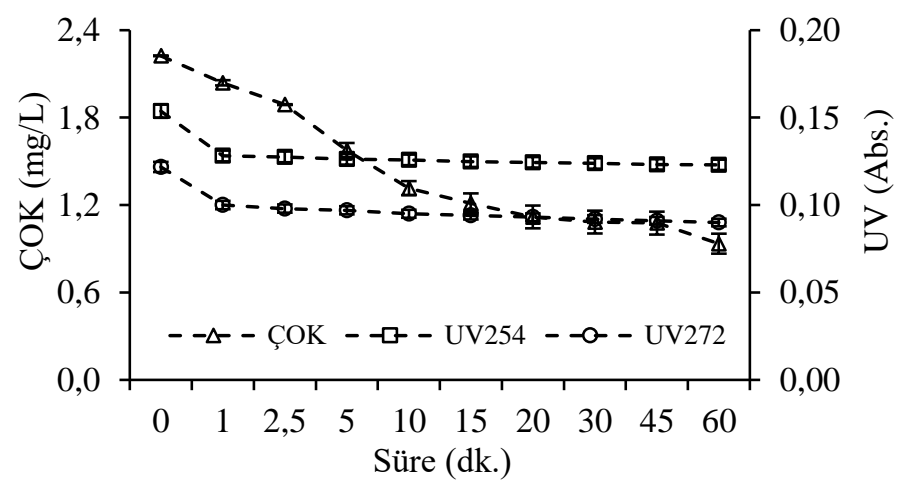

Şekil 2. nano-TiO $\mathrm{O}_{2}$ adsorpsiyonu ile DOM giderimi ([nano$\left.\mathrm{TiO}_{2}\right]=50 \mathrm{mg} / \mathrm{L},[\mathrm{HA}]=5 \mathrm{mg} / \mathrm{L}, \mathrm{pH}=7,2 \pm 0,2, n=120$ devir)

Şekil 2'de görüldüğü gibi süre artışına bağlı olarak nano- $\mathrm{TiO}_{2}$ yüzeyinde HA'nın adsorpsiyonu ÇOK göstergesine göre \%45,50'ye kadar yükseliş göstermektedir ve maksimum adsorpsiyon kapasitesi ise $45,50 \mathrm{mg} / \mathrm{g}$ olarak hesaplanmıştır. Literatürede HA giderimi için MWCNT, MWCNT-OH, MWCNT-COOH, GO ve $\mathrm{TiO}_{2}$ gibi adsorbentlerin kullanıldğ 1 çalışmalarda adsorpsiyon kapasitesi $0,57-36,7 \mathrm{mg} / \mathrm{g}$ aralığında bulunmuştur (Ly ve ark., 2020). Bu sonuç, Tablo 3'te belirtildiği gibi adsorpsiyonun gerçekleşme hızının 0,1047 1/dk olması gerekçesiyle yavaş ilerlediğini ve hümik asidin adsorpsiyonu için nano- $\mathrm{TiO}_{2}$ yüzeyindeki mevcut aktif bölgeler ile fonksiyonel hümik asit grupları arasındaki iyon ve/veya proton alışverişinin gerçekleştiğini göstermektedir. Ayrıca, hümik asit adsorpsiyon 
hızının yavaş olmasının olası bir nedeni de nano boyutlu adsorbanın çok fazla adsorpsiyon aktif bölgesi sağlamış olabilmesidir; adsorpsiyon işlemi devam ederken hümik asit konsantrasyonundaki azalma adsorbanın kimyasal adsorpsiyon performansını engellemiş olabileceği düşünülmektedir (Kim ve ark., 2013). Böylelikle zaman içerisinde adsorpsiyon hızı azalsa da hümik asidin giderim verimliliği artmaktadır. nano- $\mathrm{TiO}_{2}$ yüzeyinden adsorplanmasına bağlı olarak sucul ortamdan hümik asitin alifatik ve aromatik fraksiyonlarının ortalama \%20 civarında azaldığı görülmektedir. Adsorpsiyon prosesinin HA'y1 bozundurmaktan daha çok sucul fazdan ayrımını sağlayan bir proses olduğu görülmektedir. Adsorpsiyon prosesinde ara ürünler kısıtlı olarak oluştuğu için özellikle oksidasyonu sonucu çok fazla ara ürün oluşan kirleticilerin gideriminde etkin olarak kullanılabileceği düşünülmektedir.

Şekil 3 'te nano- $\mathrm{TiO}_{2}$ yüzeyinde adsorbe olan hümik asidin SEM fotoğrafları verilmiştir. nano- $\mathrm{TiO}_{2}$ yüzey morfolojisindeki değişim açıklıkla görülmektedir. EDS analizlerinde, HA adsorpsiyonun bir göstergesi olan karbonun atomik yüzdesi ham nano- $\mathrm{TiO}_{2}$ 'de \%12,07 iken adsorpsiyon sonrasinda \%47,20'ye yükseldiği görülmektedir.

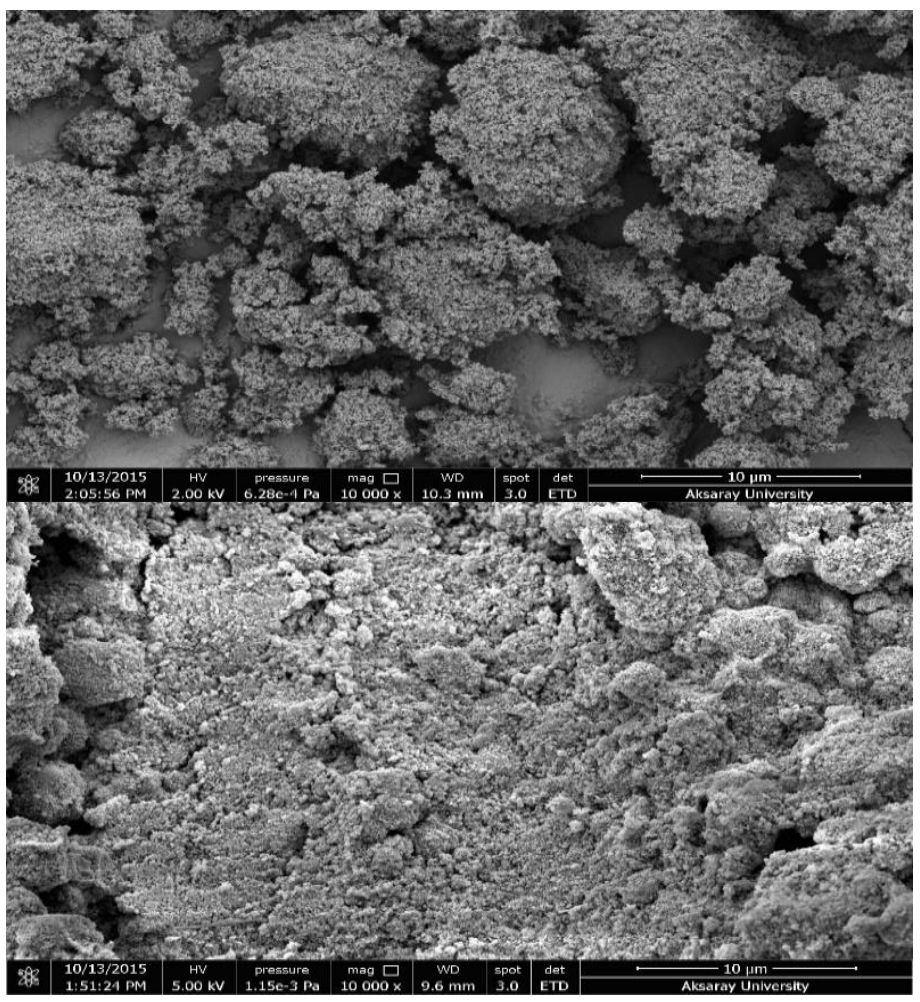

Şekil 3. nano- $\mathrm{TiO}_{2}$ yüzeyinde HA'nın adsorpsiyonu; (1) ham nano- $\mathrm{TiO}_{2}$ ve (2) $\mathrm{HA}$ adsorpsiyonu sonrast

\subsection{Katalitik Ozonlama ile DOM Giderimi}

Katalitik ozonlama proseslerinin DOM giderim verimini etkileyen en önemli değişkenlerden biri kirletici konsantrasyonu ve karakterizasyonudur. Bu başlıkta, yüzeysel su kaynaklarında bulunabilen konsantrasyonda doğal organik maddenin katalitik ozonlama ile giderimi araştırılmıştır. Temas süresi artışına bağlı olarak ÇOK ve UV indekslerindeki değişim Şekil 4 'te verilmiştir.

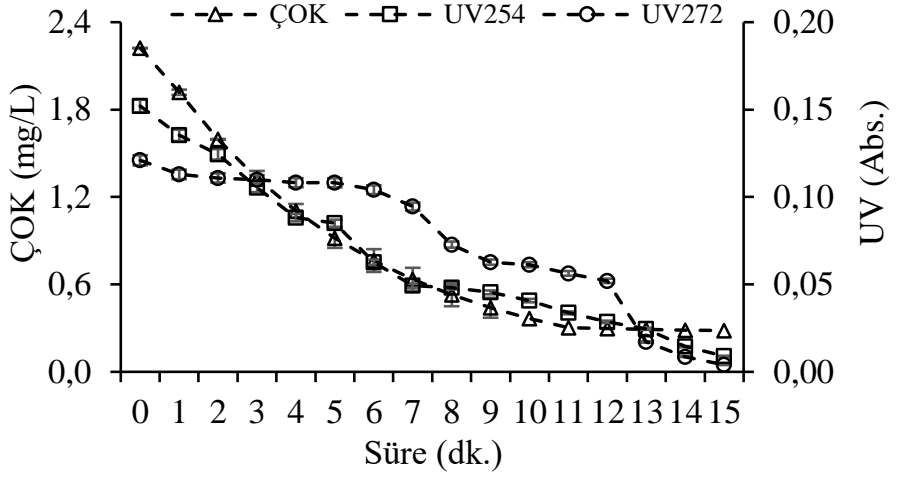

Şekil 4. Katalitik ozonlama ile DOM giderimi ([nano- $\left.\mathrm{TiO}_{2}\right]=50$ $\mathrm{mg} / \mathrm{L},\left[\mathrm{O}_{3}\right]=10 \mathrm{mg} / \mathrm{L},[\mathrm{HA}]=5 \mathrm{mg} / \mathrm{L}, \mathrm{pH}=7,2 \pm 0,2, n=120$

devir)

Şekil 4'te görüldüğü gibi katalitik ozonlama sırasında HA'nın aromatik ve alifatik yapısındaki değişim ortalama \%95'dir. HA yapısında bulunan Aromatikler, olefinler, aminler gibi doymamış gruplar ve diğer özel gruplar, moleküler ozon ve/veya serbest radikaller tarafindan oksitlenmektedir. Daha önce yaptığımız çalışmalara benzer olarak katalitik ozonlamada oluşan serbest radikallerin bir dizi küçük moleküler uçucu yan ürünün ortaya çıkmasına neden olan çift bağları kopardığı, aromatik halkaları açtığı ve alkil gruplarını oksitlediği düşünülmektedir (Alver ve ark., 2020). Serbest radikaller ile reaksiyona girmesi sonucunda organik madde bozunarak ara ürünlere ve son ürüne $\left(\mathrm{CO}_{2}\right.$ ve $\left.\mathrm{H}_{2} \mathrm{O}\right)$ dönüşmekte ve son ürüne kadar okside olan organik madde oranında ÇOK konsantrasyonlarında azalma sağlanmaktadır. Katalitik ozonlama sırasında oluşan serbest radikallerin, oksidasyonu yavaş olan HA ve oksidasyon ara ürünlerini tekil ozonlamaya göre daha hızlı bozundurduğu görülmektedir. Ayrıca, son ürüne dönüşmeyen ozonlanmış organik madde yapısının önemli bir kısmının hidrofobik ve alifatik yapıda -biyolojik olarak parçalanabilir- olduğu düşünülmektedir. Ozonlama sırasında ortam pH'sı bir miktar düşüş göstermekte $(\mathrm{pH} 6,6)$ ve asidik gruplar oluşmaktadır. Bu gruplar Leitner ve Fu (2005) tarafından yapılan çalışmada da belirtildiği gibi HA molekülleri üzerinde oluşan ya da oksidasyon sonucunda HA moleküllerinden ayrılan asidik bileşikler olabilir.

Reaksiyon süresindeki artışla ÇOK konsantrasyonu \%87 üzerinde azalmaktadır. Bu nedenle, organik maddenin alifatik ve aromatik fraksiyonlarının bağ yapısının bozundurulması için $0,050 \mathrm{~g} / \mathrm{L}$ katalizör dozu uygun bulunmuştur. Katalitik ozonlama deneylerinde reaksiyonlarının ara yüzeyde gerçekleşmesi istenilmektedir. Aksi halde, katalizör yüzeyindeki aktif bölgelerin HA tarafından dolması sonucunda HA kütle transfer kuvveti azalmakta ve katalizör yüzeyinde ozonun radikallere dönüşmesi için gerekli alan da kısıtlanmaktır diğer bir deyişle kütle transfer hızı yavaşlayacaktır. $\mathrm{Bu}$ çalışmada olduğu gibi ara yüzey rekasiyonlarında ise hem ozon hem de kirleticinin adsorplanması için yeterli alan bulunmaktadır. Bu sayade ozon hızla radikallere dönüşmekte ve oluşan radikaller katalizöür yüzeyindeki ve çözeltideki HA ile hızlıca reaksiyona girebilmektedir. Katalizör yüzeyindeki aktif bölgelerde bu yolla sürekli olarak yenilebilmekte ve katalizör yüzeyinin kısıtlayıcı etkisi ortadan kalkmaktadır. Katalitik ozonlama deneylerinde elde edilen Yalanc1 1. Derece kinetiğe uygun reaksiyon hızı 0,4780 1/dk'dır ve doğrudan radikal oluşum hızıyla bağlantılıdır. 


\subsection{Katalitik Aktivite ve Reaksiyon Kinetiklerinin Değerlendirilmesi}

Katalitik ozonlama prosesinin, tekil ozonlama ve tekil adsorpsiyona kıysala HA giderimindeki etkinliği ÇOK ve UV indeksleri üzerinden takip edilmiş ve Şekil 5'te gösterilmiştir. Tekil adsorpsiyon ve tekil ozonlama deneylerindeki reaksiyon süresi katalitik ozonlama ile aynı (15 dk.) seçilerek hesaplamalar yapilmıştır.

Heterojen katalitik ozonlama sırasında ÇOK bozunma hızı, kimyasal kinetik model kullanılarak makul bir șekilde tahmin edilebilemektedir. Pek çok kirleticinin giderimi için uygulanacak $\mathrm{O}_{3}$ ve $\mathrm{OH} \bullet$ oranları halihazırda bilinirken ve $\mathrm{O}_{3}$ ve $\mathrm{OH} \bullet$ temas süresinin belirlenmesi uygulanan arıtım esnasında kirletici giderimi verimliliğinin ve kinetiklerinin takip edilmesini gerektirmektedir (Guo ve ark., 2019; Von Sonntag Von Gunten, 2012). Bu çalışmada HA gideriminde uygulanan her bir proses için ayrı ayrı reaksiyon kinetiği hesaplanmış ve Tablo 3 'te farklı arıtım proseslerine uygulanan kinetik modellerin $\mathrm{R}^{2}$ ve kinetik parametreleri sunulmuştur.

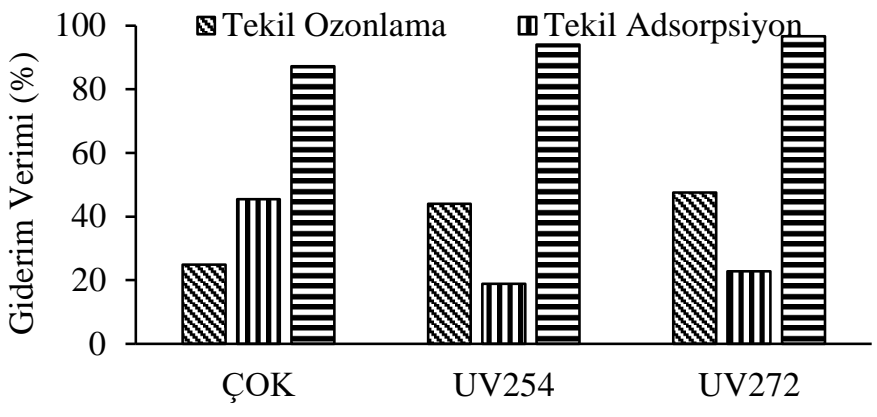

Şekil 5. Katalitik ozonlama prosesinin tekil adsorpsiyon ve tekil ozonlama ile klyaslanması ( $t=15 \mathrm{dk}$., $[C \mathrm{OKK}]=2,222 \mathrm{mg} / \mathrm{L}$, $\left[U V_{254}\right]=0,152 \mathrm{Abs} .,\left[U V_{272}\right]=0,121 \mathrm{Abs}$.)

Şekil 5'te, HA gideriminde katalitik ozonlama prosesinin tekil ozonlama ve tekil adsorpsiyonuna göre etkinliği açıkça görülmektedir. ÇOK giderim verimleri tekil adsorpsiyon, tekil ozonlama ve katalitik ozonlama sırasıyla $\% 24, \% 45$ ve $\% 87$ 'tür. Giderim verimliliklerine benzer olarak UV indekslerindeki azalım da aynı eğilimi göstermektedir. HA'nın nano- $\mathrm{TiO}_{2}$ üzerindeki adsorpsiyonu, genellikle $\mathrm{TiO}_{2}, \mathrm{MnO}_{2}, \mathrm{Al}_{2} \mathrm{O}_{3}$ ve grafen oksit vb. birçok katalizör gibi katalitik ozonlamada kirleticilerin giderimine kısıtlı olarak katkıda bulunur (Ikhlaq ve ark., 2015; Li ve ark., 2014; Wang ve ark., 2016; Xu ve ark., 2016; Zhao ve ark., 2014). Katalitik ozonlamada katalizörün asıl görevi, kirletici ile ozonu adsorbe edebilecek aktif sitelere sahip lması ve ara yüzey reaksiyonlarının oluşumunu sağlamasıdır. ÇOK giderim verimliliği artışına bağlı olarak ara yüzey reaksiyonlarının oluştuğu düşünülmektedir.

Tablo 3'te sunulan Yalancı 1. Derece reaksiyon hizları (k) karşılaştırıldığında, katalitik ozonlamada tekil ozonlamaya nazaran belirgin bir artış olduğu görülmektedir. Bu sonuç tekil ozonlamada oluşan reaksiyon mekanizmasına ilaveten daha fazla serbest radikal oluştuğu ve serbest radikallerin hem kirletici hem de ozonla reaksiyonlarının daha hızlı gerçekleştiğini göstermektedir. Nano- $\mathrm{TiO}_{2}$ katalizörü ozondan hidroksil radikali oluşma verimliliğini 4,565 $(0,4780 / 0,1047)$ kat yükseltmektedir. Nano- $\mathrm{TiO}_{2}$ 'nin ozonlamaya katkısı, literatürde daha önce HA'nın katalitik ozonlama ile giderimi üzerine çalışılan $\alpha-\mathrm{Al}_{2}(2,298)$ ve
$\mathrm{Mn}_{2} \mathrm{O}_{3}(1,562)$ gibi katalizörlerinkinden daha yüksektir (Salla ve ark., 2020).

Tablo 3. Farklı arıtım proseslerine göre kinetik parametreler

\begin{tabular}{|c|c|c|c|c|}
\hline Aritım & Model & $\mathbf{R}^{2}$ & \multicolumn{2}{|c|}{ Parametre } \\
\hline \multirow{4}{*}{$\begin{array}{l}\text { Tekil } \\
\text { ozonlama }\end{array}$} & \multirow{2}{*}{ Yalancı 1} & \multirow{2}{*}{0,993} & $\mathrm{k}_{1}(1 / \mathrm{dk})$ & $\mathrm{q}_{\mathrm{e}}(\mathrm{mg} / \mathrm{g})$ \\
\hline & & & 0,1773 & 0,328 \\
\hline & \multirow{2}{*}{ Yalancı 2} & \multirow{2}{*}{0,833} & $\mathrm{k}_{2}(\mathrm{~g} / \mathrm{mg} \mathrm{dk})$ & $\mathrm{q}_{\mathrm{e}}(\mathrm{mg} / \mathrm{g})$ \\
\hline & & & 0,0090 & 62,118 \\
\hline \multirow{4}{*}{$\begin{array}{l}\text { Tekil } \\
\text { adsorpsiyon }\end{array}$} & \multirow{2}{*}{ Yalancı 1} & \multirow{2}{*}{0,980} & $\mathrm{k}_{1}(1 / \mathrm{dk})$ & $\mathrm{q}_{\mathrm{e}}(\mathrm{mg} / \mathrm{g})$ \\
\hline & & & 0,1047 & 24,098 \\
\hline & \multirow{2}{*}{ Yalance 2} & \multirow{2}{*}{0,977} & $\mathrm{k}_{2}(\mathrm{~g} / \mathrm{mg} \mathrm{dk})$ & $\mathrm{q}_{\mathrm{e}}(\mathrm{mg} / \mathrm{g})$ \\
\hline & & & 0,0040 & 31,588 \\
\hline \multirow{4}{*}{$\begin{array}{l}\text { Katalitik } \\
\text { ozonlama }\end{array}$} & \multirow{2}{*}{ Yalance 1} & \multirow{2}{*}{0,965} & $\mathrm{k}_{1}(1 / \mathrm{dk})$ & $\mathrm{q}_{\mathrm{e}}(\mathrm{mg} / \mathrm{g})$ \\
\hline & & & 0,4780 & 96,041 \\
\hline & \multirow{2}{*}{ Yalancı 2} & \multirow{2}{*}{0,894} & $\mathrm{k}_{2}(\mathrm{~g} / \mathrm{mg} \mathrm{dk})$ & $\mathrm{q}_{\mathrm{e}}(\mathrm{mg} / \mathrm{g})$ \\
\hline & & & 0,0230 & 61,078 \\
\hline
\end{tabular}

\section{Sonuç}

$\mathrm{Bu}$ çalışmada, nano- $\mathrm{TiO}_{2}$ katalizörü HA’nın ozonlama ile bozundurulma etkinliğini arttırılmak amacıyla kullanılmıştır. Tekil ozonlama, tekil adsorpsiyon ve katalitik ozonlama deneyleri gerçekleştirilerek nano- $\mathrm{TiO}_{2}$ 'nin katalitik etkinliği HA'nın fizikokimyasal yapısındaki değişimi ve giderimi takip edilerek belirlenmiştir. HA'nın nano- $\mathrm{TiO}_{2}$ üzerinde katalitik ozonlanması, deneysel koşullar altında, tek başına ozonlamaya kıyasla sudan ÇOK uzaklaştırma verimliliğini dört katına, tekil adsorpsiyona kıyasla ise iki katına çıkardığı gözlemlenmiştir. Tüm deneyler boyunca katalitik ozonlama sisteminin, katı-sıvı ara yüzeyinde DOM'un sürekli adsorpsiyonu ve oksidasyonunun dinamik dengesinde olduğu görülmüştür. Hem tekil ozonlama hem de nano- $\mathrm{TiO}_{2} / \mathrm{O}_{3}$ prosesinin DOM'un aramotik yapısinı bozundurarak biyolojik olarak giderilebilen fraksyionunu arttırdığı görülmüştür. Çalışma sonuçları, tekil ozonlama, tekil nano- $\mathrm{TiO}_{2}$ adsorpsiyonu ve katalitik ozonlama proseslerinin organik maddenin alifatik ve aromatik fraksiyonlarının uzaklaştırılmasındaki rolünün daha iyi anlaşılmasına olanak tanımaktadir.

\section{Teşekkür}

Aksaray Üniversitesi Çevre Mühendisliği Bölümü'ne bu yayının oluşturulmasında verdiği destekler için teşekkür ederiz.

\section{Kaynakça}

Alver, A. (2019). Evaluation of conventional drinking water treatment plant efficiency according to water quality index and health risk assessment. Environmental Science and Pollution Research, 26(26), 27225-27238.

Alver, A., Basturk, E. (2019). Removal of aspartame by catalytic ozonation with nano-TiO2 coated pumice. Desalination and Water Treatment, 152, 268-275.

Alver, A., Baştürk, E., Kılıç, A. (2021). Development of adaptive neuro-fuzzy inference system model for predict 
trihalomethane formation potential in distribution network simulation test. Environmental Science and Pollution Research, 28(13), 15870-15882.

Alver, A., Kılıç, A. (2018). Catalytic ozonation by iron coated pumice for the degradation of natural organic matters. Catalysts, 8(5), 219.

Alver, A., Kılıç, A. (2021). Katalitik Ozonlanmanın Doğal Organik Maddenin Yapısına ve Trihalometan Oluşturma Potansiyeline Etkisi. Avrupa Bilim ve Teknoloji Dergisi(23), 601-607.

Alver, A., TAĞAÇ, A. A., KILIÇ, A. (2020). Gümüş nanopartiküller eşliğinde katalitik ozonlama prosesleri ile sucul ortamdan doğal organik maddelerin giderimi: Ozonlama ürünlerinin belirlenmesi. Gazi Üniversitesi Mühendislik Mimarlık Fakültesi Dergisi, 35(3), 1285-1296.

Argun, M. E., Alver, A., Karatas, M. (2017). Optimization of landfill leachate oxidation at extreme conditions and determination of micropollutants removal. Desalination and Water Treatment, 90, 130-138.

Čehovin, M., Medic, A., Scheideler, J., Mielcke, J., Ried, A., Kompare, B., Gotvajn, A. Ž. (2017). Hydrodynamic cavitation in combination with the ozone, hydrogen peroxide and the UV-based advanced oxidation processes for the removal of natural organic matter from drinking water. Ultrasonics Sonochemistry, 37, 394-404.

Faria, P., Monteiro, D., Órfão, J., Pereira, M. (2009). Cerium, manganese and cobalt oxides as catalysts for the ozonation of selected organic compounds. Chemosphere, 74(6), 818-824.

Grasso, D., Chin, Y.-p., Weber Jr, W. J. (1990). Structural and behavioral characteristics of a commercial humic acid and natural dissolved aquatic organic matter. Chemosphere, 21(10-11), 1181-1197.

Guo, Y., Zhu, S., Wang, B., Huang, J., Deng, S., Yu, G., Wang, Y. (2019). Modelling of emerging contaminant removal during heterogeneous catalytic ozonation using chemical kinetic approaches. Journal of Hazardous Materials, 380, 120888.

Ikhlaq, A., Brown, D. R., Kasprzyk-Hordern, B. (2015). Catalytic ozonation for the removal of organic contaminants in water on alumina. Applied Catalysis B: Environmental, 165, 408418.

International, A. (2004). Annual book of ASTM standards. ASTM International.

Kim, J. K., Alajmy, J., Borges, A. C., Joo, J. C., Ahn, H., Campos, L. C. (2013). Degradation of humic acid by photocatalytic reaction using nano-sized $\mathrm{ZnO} /$ laponite composite (NZLC). Water, Air, \& Soil Pollution, 224(11), 1-10.

Kulovaara, M., Corin, N., Backlund, P., Tervo, J. (1996). Impact of UV254-radiation on aquatic humic substances. Chemosphere, 33(5), 783-790.

Lagergren, S. K. (1898). About the theory of so-called adsorption of soluble substances. Sven. Vetenskapsakad. Handingarl, 24, $1-39$.

Leitner, N. K. V., Fu, H. (2005). pH effects on catalytic ozonation of carboxylic acids with metal on metal oxides catalysts. Topics in catalysis, 33(1-4), 249-256.

Li, H., Xu, B., Qi, F., Sun, D., Chen, Z. (2014). Degradation of bezafibrate in wastewater by catalytic ozonation with cobalt doped red mud: efficiency, intermediates and toxicity. Applied Catalysis B: Environmental, 152, 342-351.

Li, W.-T., Jin, J., Li, Q., Wu, C.-F., Lu, H., Zhou, Q., Li, A.-M. (2016). Developing LED UV fluorescence sensors for online monitoring DOM and predicting DBPs formation potential during water treatment. Water research, 93, 1-9.
Ly, Q. V., Maqbool, T., Zhang, Z., Van Le, Q., An, X., Hu, Y., Cho, J., Li, J., Hur, J. (2020). Characterization of dissolved organic matter for understanding the adsorption on nanomaterials in aquatic environment: A review. Chemosphere, 128690.

Mathon, B., Coquery, M., Liu, Z., Penru, Y., Guillon, A., Esperanza, M., Miège, C., Choubert, J.-M. (2021). Ozonation of 47 organic micropollutants in secondary treated municipal effluents: Direct and indirect kinetic reaction rates and modelling. Chemosphere, 262, 127969.

Miao, H., Tao, W. (2008). Ozonation of humic acid in water. Journal of Chemical Technology \& Biotechnology: International Research in Process, Environmental \& Clean Technology, 83(3), 336-344.

Rucka, K., Solipiwko-Pieścik, A., Wolska, M. (2019). Effectiveness of humic substance removal during the coagulation process. SN Applied Sciences, 1(6), 535.

Salla, J. S., Padoin, N., Amorim, S. M., Puma, G. L., Moreira, R. F. (2020). Humic acids adsorption and decomposition on $\mathrm{Mn} 2 \mathrm{O} 3$ and $\alpha-\mathrm{Al} 2 \mathrm{O} 3$ nanoparticles in aqueous suspensions in the presence of ozone. Journal of environmental chemical engineering, 8(2), 102780.

Simonin, J.-P. (2016). On the comparison of pseudo-first order and pseudo-second order rate laws in the modeling of adsorption kinetics. Chemical Engineering Journal, 300, 254-263.

Thurman, E. M. (2012). Organic geochemistry of natural waters (Vol. 2). Springer Science \& Business Media.

Von Sonntag, C., Von Gunten, U. (2012). Chemistry of ozone in water and wastewater treatment. IWA publishing.

Wang, Y., Xie, Y., Sun, H., Xiao, J., Cao, H., Wang, S. (2016). Efficient catalytic ozonation over reduced graphene oxide for p-hydroxylbenzoic acid (PHBA) destruction: active site and mechanism. ACS applied materials \& interfaces, 8(15), 9710-9720.

Wang, Y., Yu, J., Han, P., Sha, J., Li, T., An, W., Liu, J., Yang, M. (2013). Advanced oxidation of bromide-containing drinking water: A balance between bromate and trihalomethane formation control. Journal of Environmental Sciences, 25(11), 2169-2176.

Waterson, E. J., Canuel, E. A. (2008). Sources of sedimentary organic matter in the Mississippi River and adjacent Gulf of Mexico as revealed by lipid biomarker and $\delta 13 \mathrm{CTOC}$ analyses. Organic Geochemistry, 39(4), 422-439.

Weber, J., Chen, Y., Jamroz, E., Miano, T. (2018). Preface: humic substances in the environment. Journal of Soils and Sediments, 18(8), 2665-2667.

Wolska, M., Mołczan, M., Urbańska-Kozłowska, H., SolipiwkoPieścik, A. (2018). Optimizing coagulant choice for treatment technology of surface water for human consumption. Environment Protection Engineering, 44(4).

Xu, B., Qi, F., Sun, D., Chen, Z., Robert, D. (2016). Cerium doped red mud catalytic ozonation for bezafibrate degradation in wastewater: Efficiency, intermediates, and toxicity. Chemosphere, 146, 22-31.

Zhang, J., Lee, K.-H., Cui, L., Jeong, T.-s. (2009). Degradation of methylene blue in aqueous solution by ozone-based processes. Journal of Industrial and Engineering Chemistry, 15(2), 185-189.

Zhao, H., Dong, Y., Jiang, P., Wang, G., Zhang, J., Li, K., Feng, C. (2014). An $\alpha$-MnO 2 nanotube used as a novel catalyst in ozonation: performance and the mechanism. New Journal of Chemistry, 38(4), 1743-1750. 